\title{
Isotope Effects in Photochemistry: Application to Chromatic Orthogonality
}

\author{
Aurélien Blanc and Christian G. Bochet* \\ Department of Chemistry, University of Fribourg, Chemin du Musée 9, \\ CH-1700 Fribourg, Switzerland \\ christian.bochet@unifr.ch
}

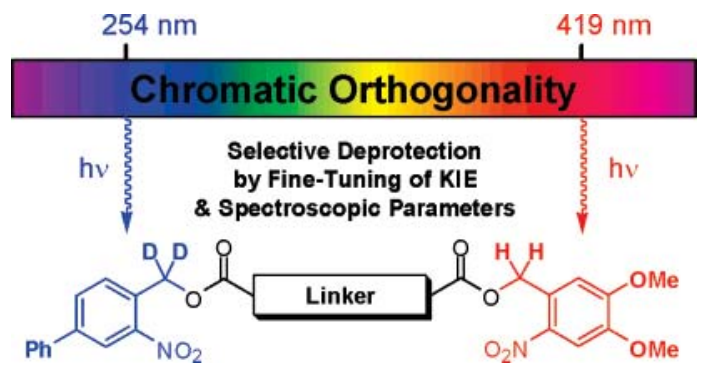

The main challenge in developing new wavelength-specific photolabile protecting groups is the rigorous control of the photolysis rate. This rate is controlled by two factors: the chromophore absorbance and the reaction quantum yield. Fine-tuning the properties by changing substituents or structural features is difficult, because both factors are independently affected. By the use of the kinetic isotope effect, we could tune the quantum yield without altering the absorbance, and hence control the overall reaction rate. We exemplified this approach with chromatically orthogonally protected diesters.

Orthogonality is the possibility of causing certain functional groups to react under a defined set of conditions without touching others. ${ }^{1}$ In the specific case of photochemical reactions, we defined chromatic orthogonality as the possibility of transforming photochemically a specific chromophore at a specific wavelength, without affecting other photosensitive moieties. $^{2}$

We were able to implement this strategy in the area of photolabile protecting groups ${ }^{3}$ by exploiting the fact that different chromophores are excited at different energies. ${ }^{4}$ Recently our own methodology was successfully applied to photolithography ${ }^{5}$ and solid-phase peptide synthesis. ${ }^{6}$ How-

(1) (a) Merrifield, R. B.; Barany, G.; Cosand, W. L.; Engelhard, M.; Mojsov, S. Pept.: Proc. Am. Pept. Symp. 5th 1977, 488. (b) Schelhaas, M.; Waldmann, H. Angew. Chem., Int. Ed. 1996, 35, 2056.

(2) Bochet, C. G. Synlett 2004, 2268.

(3) For reviews see: (a) Amit, B.; Zehavi, U.; Patchornik, A. Isr. J. Chem. 1974, 12, 103. (b) Pillai, V. N. R. Synthesis 1980, 1. (c) Pillai, V. N. R. Org. Photochem. 1987, 9, 225. (d) Bochet, C. G. J. Chem. Soc., Perkin Trans. 1 2002, 125. (e) Pelliccioli, A. P.; Wirz, J. Photochem. Photobiol. Sci. 2002, 1, 441. (f) Falvey, D. E.; Sundararajan, C. Photochem. Photobiol. Sci. 2004, 3, 831 .

(4) (a) Bochet, C. G. Angew. Chem., Int. Ed. 2001, 40, 2071. (b) Blanc, A.; Bochet, C. G. J. Org. Chem. 2002, 67, 5567. ever, very limited success was initially obtained when different groups from the same structural family (e.g., $o$-nitrobenzyl alcohol derivatives) were used. ${ }^{7}$ What makes it difficult to fine-tune the relative photochemical reaction rates of two chromophores ${ }^{8}$ is that they depend on the chromophore's absorbances and the reaction quantum yield. Both parameters are influenced by substituent effects, frequently in an unpredictable way, and sometimes in opposite directions. Recently, a very interesting structurereactivity relationship was identified on a limited number of substrates. ${ }^{9}$ However, until more knowledge is collected on the interconnection between both parameters, we decided to tackle the problem using a different approach. We considered a photochemical reaction with a low quantum

(5) del Campo, A.; Boss, D.; Spiess, H. W.; Jonas, U. Angew. Chem., Int. Ed. 2005, 44, 4707.

(6) Kessler, M.; Glatthar, R.; Giese, B.; Bochet, C. G. Org. Lett. 2003 5,1179 .

(7) Bochet, C. G. Tetrahedron Lett. 2000, 41, 6341.

(8) By reaction rate, we imply the net observed rate at constant irradiation time, and not the rate of decay of an excited state.

(9) Katritzky, A. R.; Xu, Y. J.; Vakulenko, A. V.; Wilcox, A. L.; Bley, K. R. J. Org. Chem. 2003, 68, 9100. 
yield as a pre-equilibrium between the reactant and its excited state, fluorescence and/or nonradiative relaxation being the unproductive back-reaction. Hence, any event slowing down an irreversible subsequent process will de facto reduce the reaction quantum yield by favoring the back reaction (eq 1). This was experimentally achieved by exploiting the H/D kinetic isotope effect (KIE). On substrates from the $o$ nitrobenzyl family, ${ }^{10,11}$ rate deceleration factors up to 8 were reached (Scheme 1). ${ }^{12}$ In this work, we report on the

Scheme 1. Group Differentiation Based on the KIE

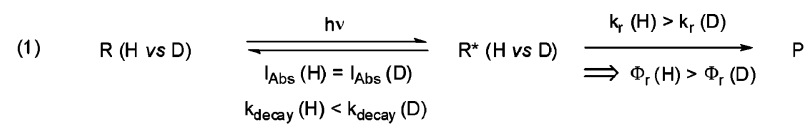

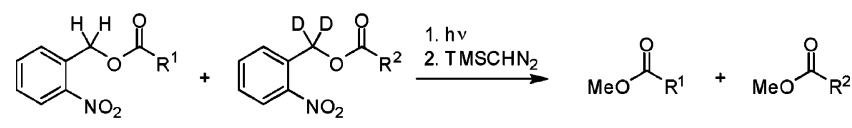

$$
\begin{aligned}
& \begin{array}{lll}
(1: 1) & 419 \mathrm{~nm}: & (8.3: 1) \\
254 \mathrm{~nm}: & (3.8: 1)
\end{array}
\end{aligned}
$$

application of this isotope effect to reach full chromatic orthogonality on bifunctional substrates.

Alcohols 1b, 1d, and 1f were deuterated at the benzylic position by reduction of the corresponding acid chlorides (prepared in situ from the acid) or ketones with sodium borodeuteride in high yields (Table 1). It was important to

Table 1. Deuterated and Hydrogenated Photolabile Alcohols

\begin{tabular}{cllllc}
\hline alcohol & $\mathrm{R}^{1}$ & $\mathrm{R}^{2}$ & $\mathrm{X}^{1}$ & $\mathrm{X}^{2}$ & yield (\%) \\
\hline $\mathbf{1 a}^{a}$ & $\mathrm{H}$ & $\mathrm{H}$ & $\mathrm{H}$ & $\mathrm{H}$ & \\
$\mathbf{1 b}$ & $\mathrm{H}$ & $\mathrm{H}$ & $\mathrm{D}$ & $\mathrm{D}$ & 94 \\
$\mathbf{1} \mathbf{c}^{a}$ & $\mathrm{OMe}$ & $\mathrm{OMe}$ & $\mathrm{H}$ & $\mathrm{H}$ & \\
$\mathbf{1 d}$ & $\mathrm{OMe}$ & $\mathrm{OMe}$ & $\mathrm{D}$ & $\mathrm{D}$ & 93 \\
$\mathbf{1 e}$ & $\mathrm{H}$ & $\mathrm{Cl}$ & $\mathrm{H}$ & $\mathrm{H}$ & 79 \\
$\mathbf{1 f}$ & $\mathrm{H}$ & $\mathrm{Cl}$ & $\mathrm{D}$ & $\mathrm{D}$ & 65 \\
$\mathbf{1} \mathbf{g}^{b}$ & $\mathrm{H}$ & $\mathrm{Ph}$ & $\mathrm{H}$ & $\mathrm{H}$ & 83 \\
$\mathbf{1 h}$ & $\mathrm{H}$ & $\mathrm{Ph}$ & $\mathrm{D}$ & $\mathrm{D}$ & 71 \\
$\mathbf{1 i}$ & \multicolumn{2}{c}{$-\mathrm{OCH}_{2} \mathrm{O}-$} & $\mathrm{Me}$ & $\mathrm{H}$ & 95
\end{tabular}

${ }^{a}$ Commercially available. ${ }^{b}$ Obtained from alcohols $1 e$ and $\mathbf{1 f}$ via Suzuki palladium cross coupling with phenylboronic acid.

avoid protic solvents and moisture during the sequence to ensure high isotopic purity.

The diesters $\mathbf{3 a}-\mathbf{h}$ were then prepared by first opening glutaric anhydride with 1 equiv of one of the alcohols $\mathbf{1 c}$,

(10) (a) Barltrop, J. A.; Plant, P. J.; Schofield, P. J. Chem. Soc., Chem. Commun. 1966, 822. (b) Patchornik, A.; Amit, B.; Woodward, R. B. J. Am. Chem. Soc. 1970, 92, 6333. (c) Cameron, J. F.; Frechet, J. M. J. J. Am. Chem. Soc. 1991, 113, 4303. (d) Holmes, C. P.; Solas, D. W.; Kiangsoontra, B. PCT Int Appl. 9410128, 1994. (e) Pirrung, M. C.; Lee, Y. R.; Park, K.; Springer, J. B. J. Org. Chem. 1999, 64, 5042. (f) Blanc, A.; Bochet, C. G. J. Org. Chem. 2003, 68, 1138. (g) Specht, A.; Goeldner, M. Angew. Chem., Int. Ed. 2004, 43, 2008. (h) Gaplovsky, M.; Il'ichev, Y V.; Kamdzhilov, Y.; Kombarova, S. V.; Mac, M.; Schwoerer, M. A.; Wirz, J. Photochem. Photobiol. Sci. 2005, 4, 33. (i) Lage Robles, J.; Bochet, C. G. Org. Lett. 2005, 7, 3545. 1d, and 1i, followed by DCC-mediated esterification with alcohols $\mathbf{1 a}, \mathbf{b}, \mathbf{e}-\mathbf{h}$. The yields were routinely higher than $70 \%$ (Table 2).

Table 2. Preparation of Photolabile Diesters

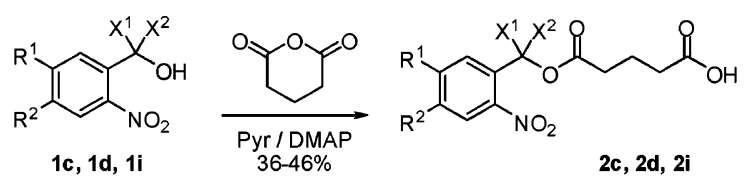

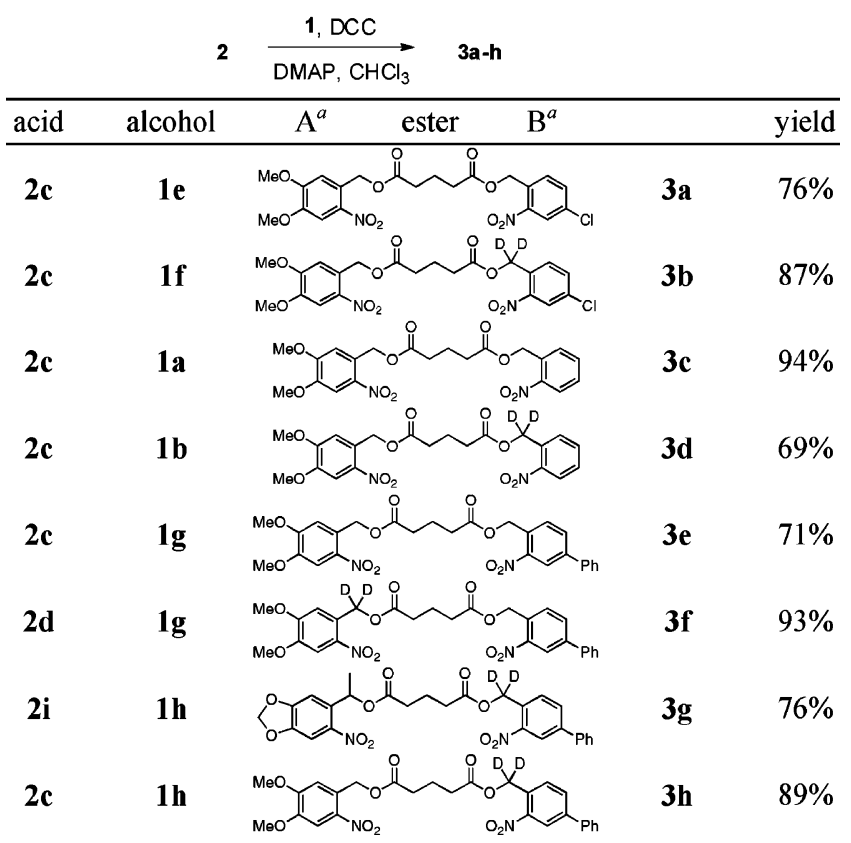

${ }^{a}$ A: "Western" terminus. B: "Eastern" terminus.

We were interested in the possibility of a real chromatic orthogonality, i.e., the deprotection of either terminus by choosing the appropriate wavelength (Figure 1; the diesters spectra are superimposable with the sum of the corresponding alcohols). To check this, we exposed the diesters $\mathbf{3 a}-\mathbf{h}$ to monochromatic light at 254 and $419 \mathrm{~nm}$. Indeed, on the basis of previous results, ${ }^{7}$ we know the rate of photolysis of hydrogenated protecting groups at these two wavelengths and that intermolecular energy transfer between two $o$-nitrobenzyl alcohol derivatives is minimal or does not exist. The results are summarized in Table 3.

As expected, the photolysis of the diesters $\mathbf{3 b}, \mathbf{d}, \mathbf{g}$ at 419 $\mathrm{nm}$ gave predominantly the monoester with deprotection at the nondeuterated site (entries 2, 5, and 10), the KIE acting as a protection against photolysis, in contrast with protic diesters 3a,c where no or poor selectivity was observed (entries 1 and 4). Knowing that the KIE was significantly reduced at shorter wavelength, ${ }^{12}$ we then examined the

(11) For recent mechanistic studies see: (a) Corrie, J. E. T.; Barth, A.; Munasinghe, V. R. N.; Trentham, D. R.; Hutter, M. C. J. Am. Chem. Soc. 2003, 125, 8546. (b) Il'ichev, Y. V. J. Phys. Chem. A 2003, 107, 10159. (c) Il'ichev, Y. V.; Schwoerer, M. A.; Wirz, J. J. Am. Chem. Soc. 2004, $126,4581$.

(12) Blanc, A.; Bochet, C. G. J. Am. Chem. Soc. 2004, 126, 7174. 


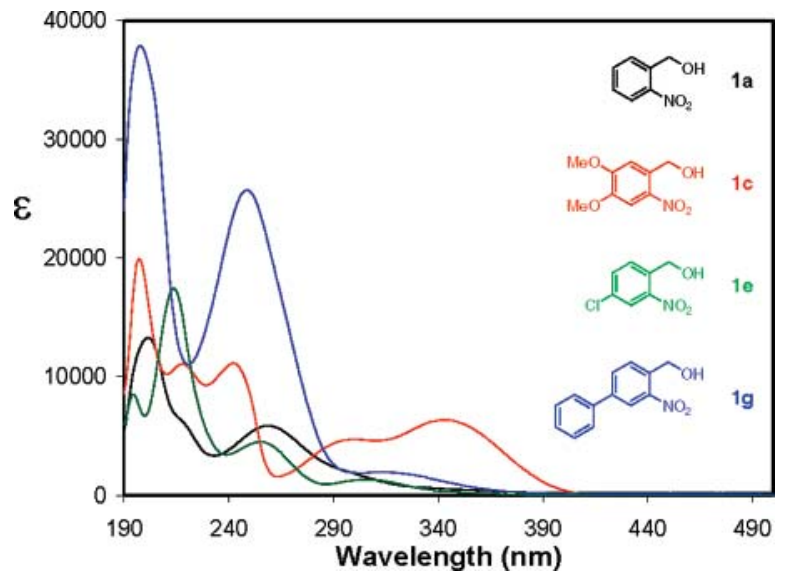

Figure 1. UV-vis spectra of photolabile groups in acetonitrile.

photolysis results at $254 \mathrm{~nm}$, an energy where we would expect little isotopic protection. Indeed, the optimization of spectroscopic (substituents) and kinetic parameters (H vs D) in the same direction should lead to the selectivity at only one wavelength. This was the case, the photolysis at high energy giving mainly a statistical deprotection of variously deprotected compounds (entries 3,6, and 11). However, by carefully choosing a protecting group pair, such as in $\mathbf{3 h}$ (entries 12 and 13), chromatic orthogonality was found (Scheme 2). Irradiation at $419 \mathrm{~nm}$ cleanly converted $\mathbf{3 h}$ into 5 after $\mathrm{TMSCHN}_{2}$ treatment with a yield of $69 \%$ and only $8 \%$ of the product of deprotection at the unwanted site

Table 3. Photolysis of Diesters with Monochromatic Light

\begin{tabular}{cccccccc}
\hline & & & & \multicolumn{4}{c}{ yield (\%) } \\
\cline { 5 - 8 } entry & diester & $\lambda(\mathrm{nm})$ & time $(\mathrm{h})$ & $\mathrm{A}^{a}$ & $\mathrm{~B}^{a}$ & $\mathrm{C}^{a}$ & $\mathrm{D}^{a}$ \\
\hline 1 & $\mathbf{3 a}$ & 419 & 48 & 37 & 15 & 33 & 15 \\
2 & $\mathbf{3 b}$ & 419 & 48 & $\mathbf{7 0}$ & 5 & 8 & 17 \\
3 & $\mathbf{3 b}$ & 254 & 1 & 30 & 28 & 17 & 25 \\
4 & $\mathbf{3 c}$ & 419 & 48 & 55 & 12 & 5 & 28 \\
5 & $\mathbf{3 d}$ & 419 & 48 & $\mathbf{8 5}$ & 2 & & 13 \\
6 & $\mathbf{3 d}$ & 254 & 1 & 25 & 22 & 20 & 33 \\
7 & $\mathbf{3 e}$ & 419 & 24 & 41 & 20 & 16 & 23 \\
8 & $\mathbf{3 e}$ & 254 & 1 & 5 & $\mathbf{7 1}$ & 11 & 13 \\
9 & $\mathbf{3 f}$ & 254 & 1 & 2 & $\mathbf{7 8}$ & 10 & 10 \\
10 & $\mathbf{3 g}$ & 419 & 10 & $\mathbf{7 7}$ & 4 & 5 & 14 \\
11 & $\mathbf{3 g}$ & 254 & 1 & 24 & 23 & 27 & 29 \\
12 & $\mathbf{3 h}$ & 419 & 40 & $\mathbf{6 9}$ & 8 & 6 & 17 \\
13 & $\mathbf{3 h}$ & 254 & 1 & 13 & $\mathbf{6 1}$ & 6 & 20
\end{tabular}

${ }^{a} \mathrm{~A}$ : Photolysis at the western terminus. B: Photolysis at the eastern terminus. C: Photolysis at both termini. D: Unreacted starting material. Yields measured spectroscopically after esterification with $\mathrm{TMSCHN}_{2}$.
Scheme 2. Chromatic Orthogonality

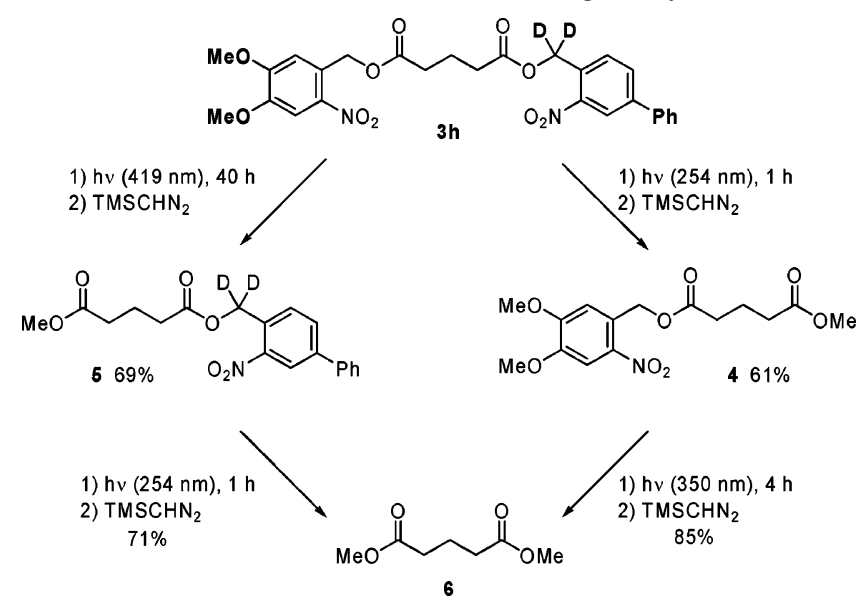

(negative control gave lower selectivity, entry 7), whereas irradiation at $254 \mathrm{~nm}$ gave 4 with $61 \%$ and $13 \%$ of the other product. Further photolysis at the complementary wavelengths converted both $\mathbf{4}$ and $\mathbf{5}$ into glutaric diester $\mathbf{6}$. This selectivity can be explained as follows: the 3,4-dimethoxy6-nitrobenzyl group is known to yield products quite efficiently despite its very low quantum yield $(\Phi=0.0013)^{13}$ because of its significant absorbance above $350 \mathrm{~nm}$ (Figure 1), whereas the 4-phenyl-6-nitrobenzyl group is highly reactive at $254 \mathrm{~nm}$ by both high quantum yield and absorbance. $^{7}$ A small reduction of $\Phi\left(k_{\mathrm{H}} / k_{\mathrm{D}}=3.6\right.$ at 254 $\mathrm{nm})^{12}$ has no major impact on its relative rate with respect to the 3,4-dimethoxy-6-nitrobenzyl group (entries 8 and 9).

In conclusion, we were able to individually control the photolysis of two photolabile protecting groups by using monochromatic light. The two groups belong to the same family of chromophores, a feature that has precluded a real reactivity difference in the past. By exploiting the slower reactivity of the deuterated compounds, we could bring selectivity into the synthetically relevant range. The combination of a fine-tuning of these protecting groups and the currently established chromatic orthogonality to provide several orthogonal dimensions is currently underway.

Acknowledgment. The financial support of the Swiss National Science Foundation (grant 620-066063) is gratefully acknowledged.

Supporting Information Available: Selected experimental procedures and spectral data. This material is available free of charge via the Internet at http://pubs.acs.org.

\section{OL070820H}

(13) (a) Reichmanis, E.; Gooden, R.; Wilkins, C. W., Jr.; Schonhorn, H. J. Polym. Sci., Polym. Chem. Ed. 1983, 21, 1075. (b) Reichmanis, E.; Smith, B. C.; Gooden, R. J. Polym. Sci., Polym. Chem. Ed. 1985, 23, 1. 